\title{
Efficacy of Philippine Ageratina Adenophoraas Home Remedy to Stop Bleedingamong Natives of Western Mountain Province
}

\author{
June II A. Kiblasan ${ }^{1}$, Rosemarie T. Bangsail ${ }^{2}$, Annie Lourie Y. Paredes ${ }^{3}$ \\ ${ }^{1}$ Public School District Supervisor, DepEd-Mountain Province, Philippines, ${ }^{2}$ Master Teacher, Banaao Elementary \\ School, Banaao, Tadian, Mt. Province, Philippines, ${ }^{3}$ Nursing Department Extension Coordinator, Mountain \\ Province State Polytechnic College, Philippines
}

\begin{abstract}
The use of home remedies in the management of minor health complaints is an area of health care that up to date has not been yet extensively researched.Regarding existing literature, there are numerous information can be heard, but scientific literature is scarce. The purpose of this study is to properly determine the efficacy of Philippine Ageratina Adenophora as home remedy to stop bleeding in minor wounds or tissue trauma. Three concentrations were determined from the extracts of the plant where tap water was the diluent. Control variable was used to see if differences exist. It has been noted that the higher the concentration of the extract, the higher its potency. It was also validated that, significant difference between the two variables was noted at which, the extract of the experimental variable has shorter clotting time than the control variable. Indeed, it is important to dessiminate the importance of the Philippine Ageratina Adenophora and learn how it will be propagated.
\end{abstract}

Keywords: Philippine Ageratina Adenophora, home remedy, coagulant, natives of Mountain Province.

\section{Introduction}

Natives in a certain locality usually depend on own culture to manage their lives at which, in terms of their health, they primarily depend on their traditions of using herbal plants.It was a claim that, herbs are natural products having chemical composition that arecommonly used by people according to the influence of their culture. These were transferred from one generation to another, race, nation and geographical location, and how it was processed that entails a sum total of the practices based on beliefs and experiences that is often enigmatic. ${ }^{1}$

Generally, cultural rootedness enduring and widespread use may indicate safety, but not the efficacy of treatments, especially on remedies containing active principlesat very low and ultra low concentrations, or relying on knowledge that was transferred to them. ${ }^{1}$ However, the use of home remedies in the management

\footnotetext{
Corresponding Author:

June II A. Kiblasan

Public School District Supervisor, Dep. Ed-Mountain Province, Philippines
}

of minor health complaints is an area of health care that up to date has not been extensively researched. One thing, numerous information can be heard, but scientific literature is scarce. ${ }^{2}$ Furthermore, the use of herbal plants is the result of many years struggles against illnesses to which man learned to pursue drugs in barks, seeds, fruit bodies, and other parts. It has been acknowledged by contemporary on the active actions that was included in modern pharmacotherapy in a range of drugs of plant origin known by ancient civilizations and used throughout the millennia. ${ }^{3}$ Moreover, the interest in phytomedicine has been renewed over the few last decades and consequently, several plant species with traditional medicinal significance have been phytochemically and pharmacologically investigated in the quest of effective and safe herbal remedies. ${ }^{4}$

Herbal remedies are prepared in several standardized ways which usually vary based upon the plant utilized, and sometimes the condition that is being treated. Methods include: infusions (hot teas), decoctions (boiled teas), tinctures (alcohol and water extracts), macerations (cold-soaking), and the making of salves and poultices. For some conditions, steam inhalation may be used. 
Among the herbal plants that wascommonly usedto stop bleeding in the western part of Mountain Province in the Cordillera Administrative Region, Philippines is the Ageratina Adenophorawhere its leaves are crushed and applied to wounds as a poultice without any knowledge of its efficacy and risks. It has been used traditionally in the previous generations yet, never been scientifically proven. This plant is common and can be seen in tropical regions not only in the Philippines but the entire world.

Ageratina Adenophorais a perennial herbaceous exotic shrub which may grow up to 1 or $2 \mathrm{~m}$ height. It has opposite trowell-shaped serrated leaves that are $6-10 \mathrm{~cm}$ long by $3-6 \mathrm{~cm}$ in width. The small compound flowers occur in late spring and summer, and are found in clusters at the end of branches. Each flower head is up to $0.5 \mathrm{~cm}$ in diam and creamy white in colour. They are followed by a small brown seed with a white feathery parachute. ${ }^{5}$

Studiesrevealedbenefits fromAgeratinaAdenophora. Kumar, Singh, Sharma and Kishore claimed that this plant produces numerous secondary metabolites, which have antimicrobial (antibacterial and antifungal), antiseptic, analgesic, molluscicides and insecticidal potential. ${ }^{6}$ Moreover, the essential oil of this plant showed significant antibacterial activity against both gram positive (Klebsiella pneumoniae and Staphylococcus aureus) and gram negative (Escherichia coli and Proteus vulgaris) bacteria. ${ }^{7}$ Further, Harish Kumar, Shanmugavadivu, Ranjithkumar\& Selvam concluded that leaf extracts of ageratinaadenophora wasfound to have a maximum antibacterial activity against tested human pathogens. Whereas, the chloroform extracts of plant's leaves can offer significant potential for the development of novel antibacterial therapies. ${ }^{8}$ On the other hand, Jigme and Bajgaiconfirmed that the aqueous extract of $\mathrm{A}$. adenophora has excellent antifungal activity against $\mathrm{A}$. candida. ${ }^{9}$ Thus, it demonstrates high potential in its use as alternative eco-friendly agent in controlling, reducing and managing A. candida infection and incidences.In spite of potentially helpful biochemical characteristics and harmful biodynamic characteristic, the potential of $A$. adenophora for controlling fungal diseases in crops has not been evaluated. ${ }^{10}$ However, despite of these literatures, the natural products profile and consequently the bioactivity of ageratinaadenophorais known to vary with the climate and geographic location of the plants. ${ }^{11}$

This practice of natives in western Mountain Province and literatures cited were the issues leading to the contextualization of this study as Firenzuoli\& Gori claimed that herbal medicine needs to be tested for efficacy using conventional trial methodology and several specific herbal extracts to be efficacious for specific condition. ${ }^{1}$ Nevertheless, the public is often misled to believe that all-natural treatments are inherently safe. At this point, this study will determine the blood coagulation effect of the Ageratina Adenophora plant extract based on various concentration through Prothrombin time test and to validate significant difference of the said extract with a commercially prepared thrombotic agent based on its clotting time.

\section{Materials and Method}

Method: The experimental design was utilized in this scientific investigatory research. The focus is on the effect of treatmentsor varied concentration of dependent variable to hold all conditions constant except the independent variable that ensures high internal validity in comparing the experimental group to the control group. If internal validity is high, differences between groups could be confidently attributed to the treatment, thus ruling out rival hypothesis will attribute on the effects to extraneous factors.

Plant Material and extract preparation: About $1 \mathrm{~kg}$ plant material (leaves and trunk) of AgeratinaAdenophora or crofton weedwas collected in the western part of Mountain Province, Cordillera Administrative Region, Philippines.It was washed thoroughly and cut into small pieces then minced using mortar and pestle. The milled mass was expressed and strained using a muslin cloth to obtain the liquid portion. The filtrates were placed in a specimen bottle and kept at room temperature.The extracts were further diluted by adding tap water to have ranges of concentration as follows: 1) $50 \%$ tap water and $50 \%$ extract, 2) $25 \%$ tap water and $75 \%$ extract, and $100 \%$ of extract.These were all kept at room temperature for 15 days. The preparation is closely similar with how Nashwa \& AboElyousrformulated their ageratinaadenophoraaqueous extract. $^{12}$

\section{Authentication of bioactive component} coagulation and treatment of data: For ethical consideration, the extract was brought to a legitimate laboratory in the capital city of the Cordillera Administrative Region for chemical analysis. This is to determine if the extract has the component to clot blood. The specimen contains bioactive component for 
blood coagulation. Thus, the specimen were brought to the municipal health center where the research was conducted for clinical trial to test its efficacy. Further, data were subsequently subjected to statisticaltreatment using theStatistical Package for SocialSciences Version 22.0 wherein, theindependent-samplest-test was used to compare the efficacy of controlled and experimental groups as home remedy to stop bleeding.

\section{Results and Discussions}

Clotting time measure the time required to form a clot. In most tests, an activator is used to initiate coagulation and test the response of a portion or portions of the cascade model of coagulation. ${ }^{13}$ According to the updated Wikipedia in 2020, clotting time is the time required for a sample of blood to coagulate in vitro under standard conditions with normal value of $3-8$ minutes ${ }^{14}$ while Ford \& Mazzaferro posed that Activated coagulation or clotting time normal value ranges from 90 to 120 seconds and 80 to 100 seconds. ${ }^{15}$ In this study, there were three (3) concentrations prepared for the experimental group used as activators to initiate blood coagulation.These are: Code001 which composed of $50 \%$ tap water and 50\% Ageratina Adenophora extract, Code 002 has concentration of $25 \%$ tap water and $75 \%$ Ageratina Adenophora extract, while Code 003 has 100\% of Ageratina Adenophora extract. On the other hand, control group used was a commercially prepared liquid substance used in simple cuts or wounds to stop bleeding which can be usually availed from a small scale store, shops and in any health center. Its concentration follows how the experimental group was prepared. Furthermore, Prothrombin time test was used to evaluate the duration of coagulation effect of the experimentaland control variables. Blood samples were taken from healthy volunteers to finally assess clotting time of the control and the experimental variables. The replication of the drop of blood is done after every 15 minutes.

Clotting Time: Table 1 revealed the result of testingof the two different variables if how many seconds it takes for the blood to clot. The number of seconds were recorded in 3 trials per variable based on its preparation.

Table 1. Clotting time of variables by trials

\begin{tabular}{|l|c|c|c|}
\hline \multirow{2}{*}{ Variables } & \multicolumn{3}{|c|}{ Trials } \\
\cline { 2 - 4 } & Code001 & Code002 & Code003 \\
\hline Control & $198 \mathrm{sec}$. & $177 \mathrm{sec}$. & $179 \mathrm{sec}$. \\
\hline Experimental & $168 \mathrm{sec}$. & $145 \mathrm{sec}$. & $142 \mathrm{sec}$. \\
\hline
\end{tabular}

From the table, the experimental blood clots at 2.36 minutes - 2.8 minutes compared to the control which is 2.98 to 3.3 minutes which means that the Philippine Ageratina Adenophora extract coagulated the blood faster.Moreover, the higher the concentration of the extract, the faster it cause blood coagulation and bleeding shortly stops.At this point, the culturally practiced home remedy to stop bleeding is practically effective than the commercially prepared substance that can be bought in a store or taken from the health center. Indeed, an advantage for people who use the indigenous herbal plantas home remedy to stop bleeding not worrying where to get an amount for the purchase or where to avail commercially prepared drug since the Philippine Ageratina Adenophora can be found anywhere even when they are at the farm. The only thing to do that is essential is, on how people understand the importance and use of this weed so they will not just take it away if found in their farm. Instead, find ways on how this plant can be propagated and its proper care.

Difference inclotting time: Most of the time, people believes on things coming outside for the notion that it has quality. This made people most believe on products coming outside than locally developed one at which, itis the same in research. Simple output do not justify the quality of the findings. This made the researchers subject their finding to further test that can validate its reality. At this point, to validate if there is significant difference between theefficacy of controlled and experimental groups as home remedy to stop bleeding, an independent-samples $t$-test was utilized.

\section{Table 2. Significant difference on clotting time of two variables}

\begin{tabular}{|c|c|c|c|c|c|}
\hline Variables & Mean & $\begin{array}{l}\text { Standard } \\
\text { Deviation }\end{array}$ & $\mathbf{t}$ & df & p-value \\
\hline Control group & 151.67 & 14.22 & \multirow[b]{2}{*}{-3.12} & \multirow[b]{2}{*}{4} & \multirow[b]{2}{*}{0.04} \\
\hline $\begin{array}{l}\text { Experimental } \\
\text { group }\end{array}$ & 184.67 & 11.59 & & & \\
\hline
\end{tabular}

It was gleaned from the table that, the result revealed a statistically reliable difference between the mean number of controlled group ( $\mathrm{M}=151.67, \mathrm{SD}=14.22)$ and experimental group $(\mathrm{M}=184.67, \mathrm{SD}=11.59)$ where condition of $t(4)=-3.12$ and $\mathrm{p}=0.04$ at $\alpha=.05$.Thus, results suggested that the experimental group is more effective in blood coagulation than the control group. With the result, it only proves that naturally prepared medication is more effective than that of commercially 
prepared for some additive that affects its potency. Indeed, It is important to dessiminate the finding to people in the community how important the weed they are considering not useful in their environment.

\section{Conclusion}

The finding shows thatnatural product is the most effective yet, it can be easily prepared for free. The only thing it need is the effort and interest of people. Moreover, its abundance in every part of the country exist and can easily propagate if intended. However, though it was traditionally used, its importance was not that much known for whatpeople knew is just a weed that hinder growth of their plants. Therefore, it is highly recommended to disseminate its importance and on how it will be propagated. One thing, further study to explore other health benefits as stated in the literature to maximize its utilization that is beneficial to the community.

Conflict of Interest: There is no professional,personal or family allegiance, bias, inclination, obligationor loyalty which may in any way affects the objectivity,independence or impartiality in the accomplishment ofthis study.

Funding: This research did not receive any specificgrant from funding agencies in the public, commercial,or non-for-profit sectors.

Ethical Clearance: Guidelines for the protectionof human rights outlined in the American Nurses Association ${ }^{16}$ was observed.

\section{References}

1. Firenzuoli F, Gori L. Herbal medicine today: clinical and research issues. Evid Based Complement Alternat Med. 2007;4(Suppl 1):37-40. doi:10.1093/ ecam/nem096

2. Parisius LM, Schröer BS, Berger S, Hermann $\mathrm{K}$ and Joos S. Use of home remedies: a crosssectional survey of patients in Germany. BMC Fam Prac, 2014, 15:116. http://www.biomedcentral. com/1471-2296/15/116

3. Petrovska BB. "Historical review of medicinal plants' usage." Pharmacognosy reviews vol. 6,11 (2012): 1-5. doi:10.4103/0973-7847.95849
4. Tripathi YC, Saini N, Anjum N, Verma PK. A Review of Ethnomedicinal, Phytochemical, Pharmacological and Toxicological Aspects of Eupatorium adenophorumSpreng. Asian $\mathrm{J}$ of Biomed and Phar Sci. August 2018, DOI: 10.13140/ RG.2.2.25513.44642

5. Rajeswary $\mathrm{M}$ and Govindarajan $\mathrm{M}$. Mosquito larvicidal and phytochemical properties of Ageratinaadenophora (Asteraceae) against three important mosquitoes. The Free Library 01 June 2013. Available from https://www.thefreelibrary. com/Mosquito larvicidal and phytochemical properties of Ageratina...-a0339203262.

6. Kumar N, Singh A, Sharma DK \& Kishore K. Evaluation of Wound Healing Activity of Ageratinaadenophora(Spreng.) R. M. King \& H. Rob. Int J of Phar Res Heal Sci,2017, 5(5), 18731876. doi:10.21276/ijprhs.2017.05.10

7. Subba B and Kandel RC. Chemical Composition and Bioactivity of Essential Oil of Ageratinaadenophora from Bhaktapur District of Nepal. J. Nepal Chem. Soc., vol. 30, 2012DOI: 10.3126/jncs.v30i0.9350

8. Harish Kumar K, Shanmugavadivu M, Ranjithkumar R \& Selvam K. Antibacterial activity of leaf extracts of Ageratinaadenophora L medicinal plant of Nilgiris Hill, Tamilnadu against human pathogens. Int.J.Biosci.Nanosci. Vol (1)1, 2014.

9. JigmeJ \&Bajgai RC. Efficacy of Ageratinaadenophoraagainst White rust (Albugo candida): A laboratory andfield study Bhutanese $\mathbf{J}$ of Agri, 2019 2(1) 26-34

10. Sobrinho ACN, de Morais S M, de Souza EB \& dos Santos Fontenelle RO. The genus Eupatorium L.(Asteraceae): A review of their antimicrobial activity. J of Med Plants Res, 2017-11(3), 43-57.

11. Burt S. Essential oils: Their antibacterial properties and potential applications in foods - A review. Int $\mathrm{J}$ of Food Microbiology, 2004, 94, 223-253.

12. Nashwa SMA \& Abo-Elyousr KAM. Evaluation of various plant extracts against the early blight disease of tomato plants under greenhouse and field conditions. Plant Protection Sci, 2012, 48(2), 7479.

13. Epstein KL. Robinson's Current Therapy in Equine Medicine (Seventh Edition), Elsevier 2015, Pages 500-502 
14. Wikipedia. Viewed at https://en.wikipedia.org/ wiki/Clotting_time. last edited on 24 March 2020.

15. Ford RB and Mazzaferro EM. Kirk \&Bistner's Handbook of Veterinary Procedures and Emergency Treatment (Ninth Edition), Elsevier 2012, Pages 551-634.
16. Wood GL, Haber J. Nursing research method critical appraised and utilization. St. Louis, Missouri: Mosby, Inc.; 2002. 